\title{
The influence of high doses of a-tocopherol on the content of selected trace elements in the liver of developing chicken embryos in experimentally induced 2,3,7,8-tetrachlorodibenzo- p-dioxin intoxication
}

\author{
Piotr Kuropka1, Maciej Dobrzynski², Malgorzata Tarnowska³, Marzena Styczynska4, \\ Krzysztof Dudek ${ }^{5}$, Anna Leskow ${ }^{3}$ and Rafal J. Wiglusz ${ }^{6} \square$
}

'Department of Histology and Embriology, Wroclaw University of Environmental and Life Sciences, Wrocław, Poland; ${ }^{2}$ Department of Conservative Dentistry and Pedodontics, Wroclaw Medical University, Wrocław, Poland; ${ }^{3}$ Department of Nervous System Diseases, Wroclaw Medical University, Wrocław, Poland; 4Department of Human Nutrition, Wroclaw University of Environmental and Life Science, Wrocław, Poland; ${ }^{5}$ Faculty of Mechanical Engineering, Technical University of Wroclaw, Wrocław, Poland; ${ }^{6}$ nstitute of Low Temperature and Structure Research, Polish Academy of Sciences, Wrocław, Poland

\begin{abstract}
A chicken embryo develops in ovo without access to a constant circulating maternal nutrient supply, and therefore all necessary nutrients are initially stored in the yolk, and with progressive development are transferred to the liver, where they are taken up in response to various needs. Fluctuations in hepatic trace elements correlate with their mobilization from egg stores. 2,3,7,8-Tetrachlorodibenzo-p-dioxin (TCDD) intoxication causes liver damage by production of free radicals, while a-tocopherol is a well-known antioxidant and may play a protective role. In the experiment presented here, a solution containing only TCDD, TCDD and a-tocopherol, as well as a-tocopherol exclusively, was administrated into the yolk sac. The iron, zinc, copper and magnesium distribution was evaluated using histological and chemical methods. It has been found that a-tocopherol has no influence on magnesium and zinc content in the liver. The observed increase in iron content may be caused by antagonistic action of iron and a-tocopherol. On the other hand, synergistic action of a-tocopherol and TCDD has been noted with respect to the copper content.
\end{abstract}

Key words: dioxin, toxicity, chicken, trace elements, a-tocopherol, liver

Received: 13 March, 2019; revised: 02 April, 2019; accepted: 09 April, 2019; available on-line: 13 April, 2019

छe-mail: R.Wiglusz@intibs.pl

Acknowledgements: This research was supported by statutory research and development activity funds assigned to the Faculty of Veterinary Medicine, Wroclaw University of Environmental and Life Sciences, as well as the National Science Center (Poland) over the course of realization of projects "Preparation and characterization of nanoapatites doped with rare earth ions and their biocomposites" (no. UMO-2012/05/E/ST5/03904) and "Preparation and characterization of biocomposites based on nanoapatites for theranostic" (no. UMO-2015/19/B/ST5/01330)

Abbreviations: DMSO, dimethyl sulfoxide; TCDD, 2,3,7,8-tetrachlorodibenzo-p-dioxin

\section{INTRODUCTION}

Unlike the mammalian fetus, the chick embryo develops in ovo without access to a constant circulating maternal nutrient supply. Instead, all of the nutrients required for the rapid growth and complete development of the offspring are deposited by the hen into the egg at the time of its formation (White, 1991). Beside mRNA, amino acids and fat stored in the yolk, trace elements, such as zinc, copper, iron and magnesium, are also essential nutrients required in small amounts for normal growth and development (Miles, 2000). During embryogenesis, trace elements stored in the yolk have to be transferred to developing tissues. Endodermal cells are in direct contact with the yolk and therefore control the uptake of yolk granules and their transport to the target organs (Richards, 1991b). Deficiencies in trace elements have been found to cause impaired growth, abnormal development of all major organ systems and, in case of extreme deficiencies, death of the embryo. Trace elements serve as co-factors of enzymes and other proteins which are contained in multiple cells (Richards \& Steele, 1987). Conversely, excessive amounts of trace elements, especially those that are acutely toxic, such as iron, can be equally detrimental to the developing embryo. There is a number of reports describing selective embryotoxic and teratogenic effects of trace element solution injections into chicken eggs early in the development (Birge, Roberts, \& Black, 1976; Gilani \& Alibhai, 1990; Mas \& Arola, 1985).

The most important organ for the storage and regulation of trace element metabolism in the developing avian embryo is the liver. Concentration of trace elements in the liver increases and decreases depending on the stage of the embryo development. Fluctuations in hepatic trace elements correlate with their mobilization from the egg stores (Richards, 1991b; Richards, 1991a).

During development, daily changes in the iron and copper content in the liver can be observed from the 10th day until hatching. The copper content increases at approximately the same rate until the 17 th day, after which it remains fairly constant. The percentage of iron in the liver (per unit of dry tissue) decreases from the 13th until the 21st day, in an inverse ratio to the dry weight of the liver. The proportion of total iron, copper and zinc concentrated in the liver decreases during the later stages of incubation (Sandrock, Kern, \& Bryan, 1983; Taschetto et al., 2017)

This indicates that the content of trace elements in the liver is not constant for each element, and their transport depends on the needs of developing organs. This transport may be interrupted by numerous toxic compounds which an intoxicated mother may deposit in the yolk. The 2,3,7,8-tetrachlorodibenzo-p-dioxin (TCDD) is a 
polychlorinated dibenzo- $p$-dioxin which is usually formed as a side product in organic synthesis and burning of organic materials, and which participates in numerous toxic interactions in the living organisms. In the contaminated areas, dioxins are present in all environmental media: the air, water and soil. They are known to be persistent, bioaccumulative and bio-reinforced (Całkosiński et al., 2014; Dobrzyński et al., 2009). In case of poultry, the main sources of exposure to TCDD intoxication include soil, commercial organic feeds, non-commercial organic feeds, plants and insects. After TCDD is ingested by a hen, the compound is accumulated in the egg fat. Increased TCDD levels are found in the free-range system eggs due to the fact that hens are more exposed to TCDD in a free-range production system. In a chicken embryo, TCDD administered into the yolk may alter development of numerous organs, including the liver (De Vries, Kwakkel, \& Kijlstra, 2006; Gostomska-Pampuch et al., 2017). In one study, Całkosiński (Całkosiński, 2008) exposed rats to TCDD and treated them for 3 weeks with high $\alpha$-tocopherol doses (30 mg/(kg b.w. daily)). The authors had found that $\alpha$-tocopherol had effectively decreased concentrations of proinflammatory cytokines in the serum, limiting inflammation and damage caused by TCDD. The antioxidant properties of $\alpha$-tocopherol have been also demonstrated in mice exposed to TCDD. Injection of a single dose of $150 \mathrm{mg} / \mathrm{kg} \mathrm{b.w}$. of $\alpha$-tocopherol followed by administration of $40 \mathrm{mg} / \mathrm{kg}$ b.w. doses for five consecutive days had significantly decreased the symptoms of TCDD poisoning (Całkosiński, 2008; Całkosiński et al., 2013). Therefore, the aim of this study was to determine the influence of TCDD on the content of selected elements in the liver and a possible protective role of $\alpha$-tocopherol in the iron distribution.

\section{MATERIALS AND METHODS}

Ethical approval. Ethical approval was not required for this study, in accordance with the EU Directive of 22 September 2010 on the protection of animals used for scientific purposes (2010/63/EU) and the Polish Act of 15 January 2015 on the protection of animals used for scientific or educational purposes (Polish Journal of Laws of 2015, item 266).

Chemicals used in the experiments. A standard solution containing $1 \mu \mathrm{g} / \mathrm{ml}$ TCDD (DD-2378-S; Greyhound Chromatography and Allied Chemicals, Birkenhead, UK) in 1\% dimethyl sulfoxide (DMSO) (Sigma-Aldrich, St. Louis, MO, USA) was prepared. A $1 \mathrm{ml}$ aliquot of a solution containing $\alpha$-tocopherol acetate (Hasco-Lek, Poland) was mixed with $800 \mu$ l of $1 \%$ DMSO to give a final $\alpha$-tocopherol acetate concentration of 300 $\mathrm{mg} / \mathrm{ml}$.

Experimental groups. Hubbard Flex line chicken eggs with a mean weight of $60 \mathrm{~g}$ were divided into four groups. The groups and treatments are described below:

Group 1 - Control group (not injected) - 5 eggs;

Group 2 - Injected with $5 \mu$ l of the TCDD standard solution ( $5 \mathrm{ng} / \mathrm{egg}$, equivalent to $0.08 \mathrm{ng} / \mathrm{g}$ ) - 10 eggs;

Group 3 - Injected with $5 \mu$ l of the TCDD standard solution ( $5 \mathrm{ng} / \mathrm{egg}$, equivalent to $0.08 \mathrm{ng} / \mathrm{g}$ ) and $10 \mu \mathrm{l}$ of the $\alpha$-tocopherol solution (1.8 $\mathrm{mg} / \mathrm{egg}$, equivalent to 30 $\mu \mathrm{g} / \mathrm{g})$ - 10 eggs;

Group 4 - Injected with $10 \mu \mathrm{l}$ of the $\alpha$-tocopherol solution $(1.8 \mathrm{mg} / \mathrm{egg}$, equivalent to $30 \mu \mathrm{g} / \mathrm{g})-10$ eggs.

The TCDD dose and the influence of DMSO on chicken embryo development were determined after inspection of previously published data (Cohen-
Barnhouse et al., 2011; Henschel, Wenzel, Diedrich, $\&$ Fliedner, 1997). The $\alpha$-tocopherol dose was determined from the results of studies conducted by Całkosiński and others (Całkosiński et al., 2011). The surface of each egg shell was disinfected with $70 \%$ ethanol; then, a small hole was drilled at the blunt end of the egg. With the egg orientated horizontally, the specified solution was injected into the yolk by inserting the needle of a Hamilton syringe through the air chamber to a depth of approx. $3 \mathrm{~cm}$. The needle was then withdrawn and the egg orientated vertically before the hole was sealed with melted paraffin (Blankenship et al., 2003). The eggs were placed in a C-82 incubator (Jartom, Gostyn, Poland) one day after being injected. The incubator was kept at $37.6^{\circ} \mathrm{C}$ and $55 \%$ humidity, and the eggs were turned $90^{\circ}$ every hour. Thiopental (Biochemie GmbH, Austria) was injected intraperitoneally at a dose of $120 \mathrm{mg} / \mathrm{kg}$ bw on the 13th day of incubation. The liver for histological and trace element analysis was removed and the material was fixed in a $4 \%$ buffered formalin solution for histological analysis.

Determination of chemical element contents in the liver. Elements were determined on the basis of the atomic spectrometry method.

Wet mineralization of samples in a closed microwave system was carried out. $5 \mathrm{~cm}^{3}$ of concentrated nitric (V) acid and $1 \mathrm{~cm}^{3}$ of concentrated hydrogen peroxide were added to the homogeneous sample weight (from $0.1 \mathrm{~g}$ to $0.5 \mathrm{~g}$ ) and then the samples were mineralized with the use of a MARS 5 microwave accelerated reaction system. Mineralizates were transferred quantitatively into $10 \mathrm{~cm}^{3}$ measurement vessels with the use of redistilled water. The mineralization process was carried out in accordance with the Polish Standard PN-EN 13805:2003. Determination of magnesium, iron and zinc content using atomic absorption spectrometry (AAS:. the analysis of magnesium, zinc and iron content was performed in an acetylene/oxygen flame by means of absorption atomic spectrometry with the use of a SpectraAA atomic absorption spectrometer equipped with the AA240FS accessory for working in a flame (Varian). Measurements of magnesium, zinc and iron content were performed in accordance with the PN-EN 14084:2004 standard in the Food Testing Laboratory of the Wroclaw University of Environmental and Life Sciences. The methods employed were confirmed through application of certified reference material (BCR-185R Bovine Liver), the unreliability of measurements was assessed at $5 \%$.

Statistical analysis. Distributions of the data concerning concentration of elements in the liver differed from normal distribution; in the Shapiro-Wilk test, they were presented in the form of median, quartile intervals (lower \& upper quartiles) and extreme values (Min-Max). The significance of differences between the average values in tested groups was verified using the non-parametric Kruskal-Wallis ANOVA by Ranks test. A two-tailed value of $p<0.05$ was used to reject the null hypothesis. All statistical analyses were performed using STATISTICA v.13 (StatSoft, Inc., Tulsa, OK, USA).

Histological analysis. For histological evaluation of iron distribution in the liver, the material was fixed in a $4 \%$ buffered formalin solution for 3 days, then washed with tap water for 24 hours, dehydrated in alcohol series and embedded in paraffin. $5 \mu \mathrm{m}$ thick sections were 



Figure 1. Statistically significant differences between the content of elements in the chicken livers.

routinely stained with hematoxylin and eosin and with an iron staining kit (Sigma) of our own modification.

\section{RESULTS}

\section{Elemental analysis}

Statistically significant differences in the copper content were observed in groups 1 and 3 ( $p<0.001)$; the same was true for magnesium in groups 2 and 3 $(p<0.01)$ and zinc in groups 2 and 3. Moderate increase in the iron content was observed in groups 2, 3 and 4 (see Fig. 1). Copper content in the liver (see Fig. 2) was significantly higher in subjects from groups 2 and 4 $(p<0.001)$. No interaction was observed in group 3. The amount of magnesium in the liver (see Fig. 3) was significantly higher in group 3. A statistically significant interaction was also observed in group 4. Group 2 was characterized by a significant decrease in magnesium content. The concentration of zinc in the liver (please see Fig. 4) was significantly higher in subjects from groups 3 and 4 . A statistically significant decrease in the zinc content was noted in group 2 .

\section{Histological examination results}

For group 1, large sinusoidal-type vessels were found in many areas, and they formed a network containing blood cells (Fig. 5a). The accompanying hepatocytes were organized into lobules. Numerous small lipid droplets were found in hepatocytes in the entire lobule.
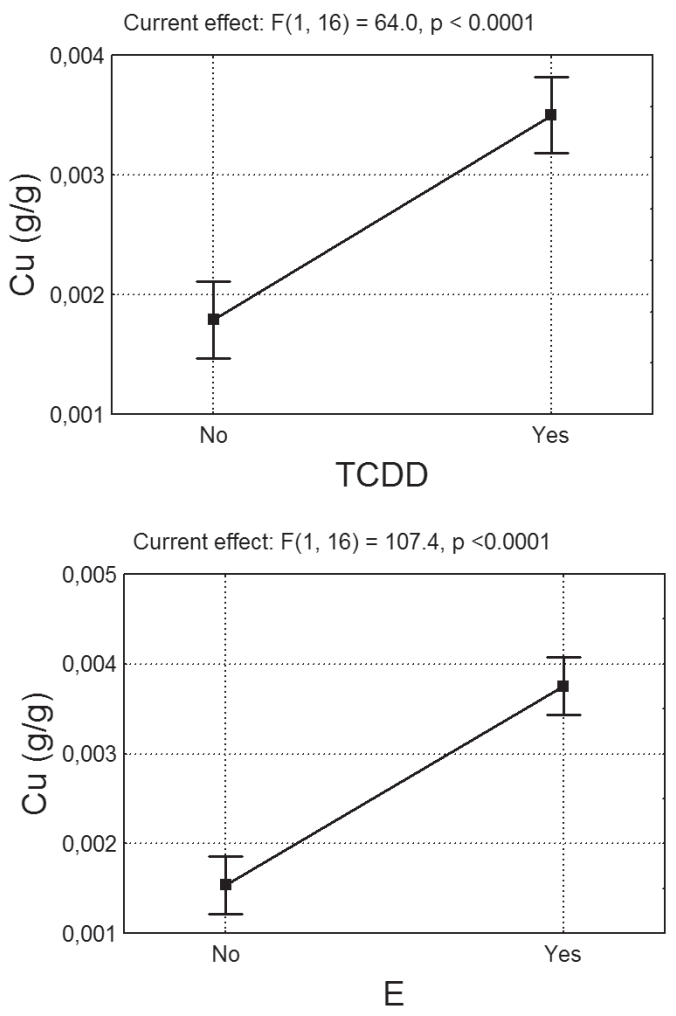

Figure 2. Copper content in the liver. 

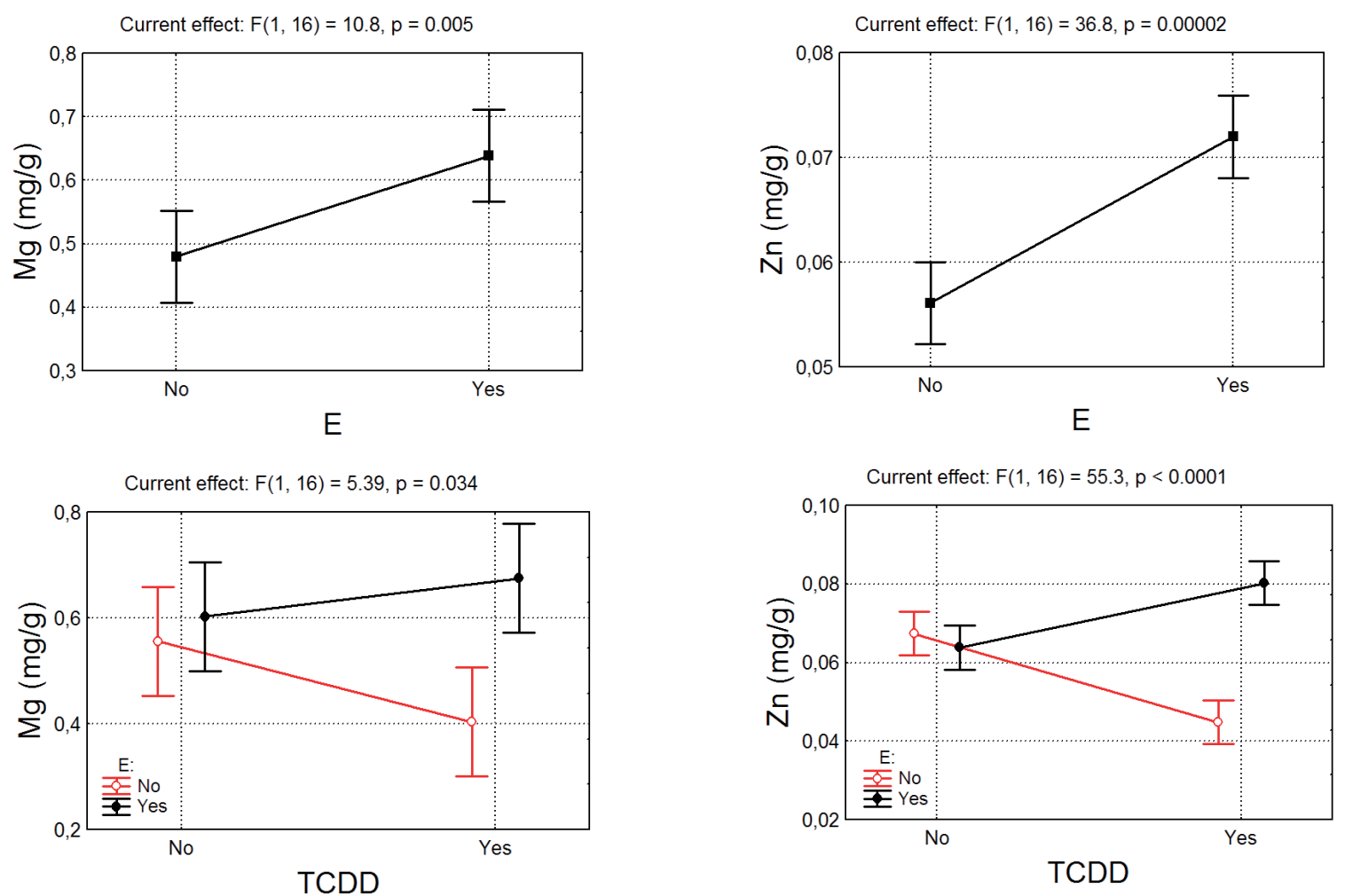

Figure 3. Magnesium content in the liver.

Figure 4. Zinc content in the liver.

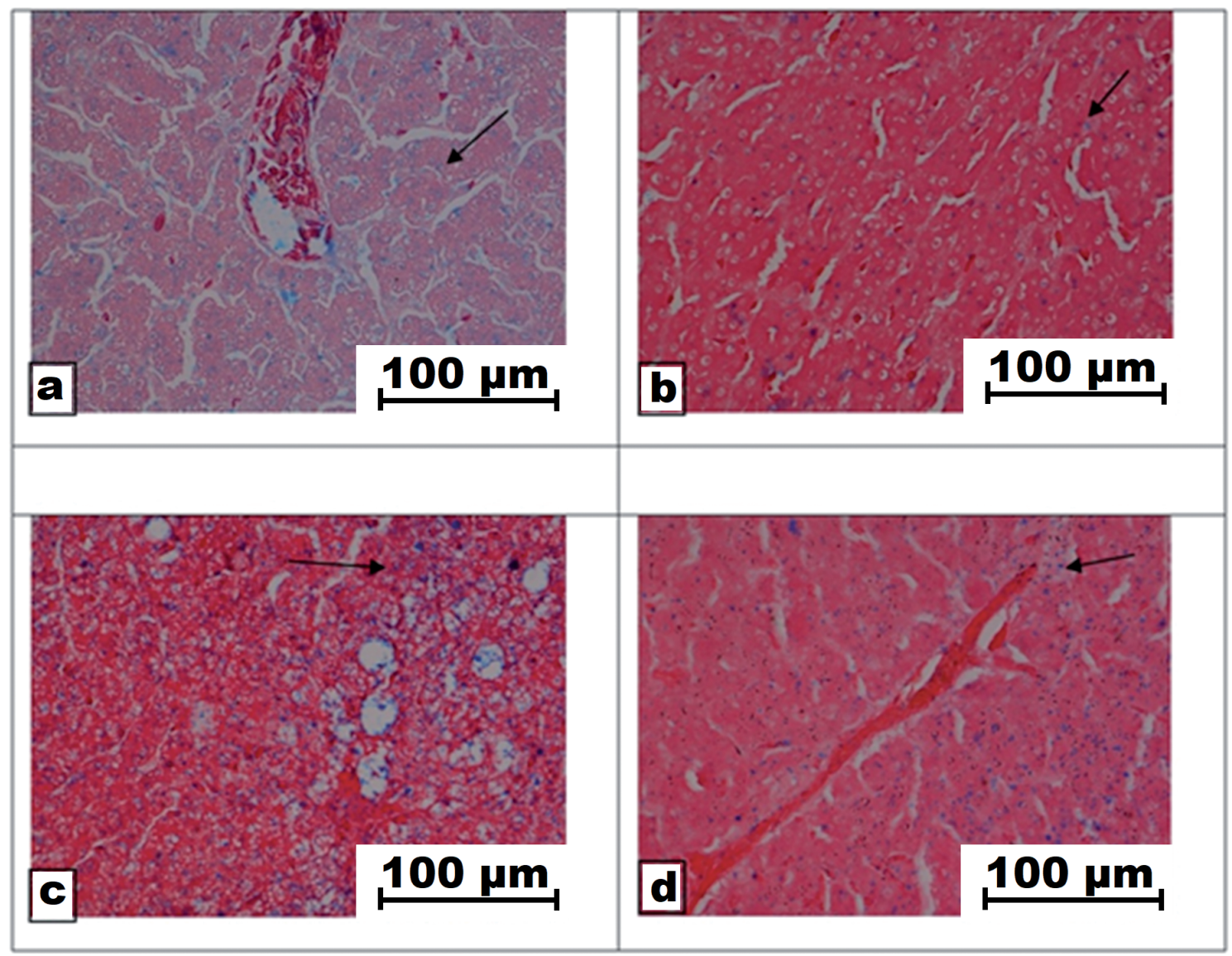

Figure 5. Iron distribution in the liver in all experimental groups (arrow). (a) group 1; (b) group 2; (c) group 3; (d) group 4. Prussian Blue, Mag. 400x. 
Hepatocytes had a large, ovoid, single nucleus and were the size of adult liver hepatocytes. Bile ducts within lobules were poorly visible. Hepatocytes from all areas contained small granules of iron. A minute amount of iron was also found in the hepatic macrophages.

Similar hepatic development was observed in embryos in the group injected with TCDD (group 2), but the positive histochemical reactions were not uniformly dispersed over the surface of the liver (Fig. 5b). The highest concentration was visible around the central vein and the periphery of the lobule. Large fat droplets in hepatocytes were visible in the area surrounding the central vein. Bile ducts were locally prevalent and visible between the hepatocytes. Livers of embryos from the group treated with TCDD and $\alpha$-tocopherol (group 3) had areas where less morphological differentiation had occurred than expected, and iron positive reaction was expressed in the form of greater amount of granules in groups 1 and 2 (Fig. 5c). Fat droplets and lymphocytic infiltrations were found in areas between cells. Hepatocytes in these areas showed regressive changes and numerous positive reactions for iron. No iron was noted in macrophages. Livers of embryos from the group injected with $\alpha$-tocopherol (group 4) were less differentiated than the control group livers (Fig. 5d). Numerous cells exhibited iron aggregates. Large veins and arteries were filled with blood. Sinusoids were narrow and did not contain erythrocytes. Cytoplasm of hepatocytes did not contain a large number of lipid droplets. Bile ducts within lobule were not visible.

\section{DISCUSSION}

Dioxins affect the body in multiple ways, causing reproduction and development disorders, immunotoxicity, thymus involution, liver damage, and cancer. Moreover, dioxin exposure results in formation of reactive oxygen species which cause oxidative stress in cells and tissues, and stimulate inflammation. Treatment with $\alpha$-tocopherol has been found to decrease concentration of nitrogen peroxide and the incidence of damage to single-stranded DNA (Alsharif \& Hassoun, 2004). Hilscherova and others (Hilscherova et al., 2003) had found that dioxins cause oxidative DNA damage in chicken embryo livers by increasing the amounts of reactive oxygen species produced and depleting glutathione. In a study conducted by Gostomska-Pampuch and others (GostomskaPampuch et al., 2017), TCDD and $\alpha$-tocopherol caused delayed liver development. In our study, the retarded growth of the liver may explain the statistically nonsignificant and small increase in the iron content in all experimental groups. Moreover, different distribution in experimental groups was observed; lack of iron in hepatic macrophages is particularly noteworthy. Iron plays an important role in lipid peroxydation and in a wide variety of biochemical processes, and is a required co-factor for the function of over one hundred different enzymes, while $\alpha$-tocopherol has strong antiperoxidant properties. The critical role of $\mathrm{Fe}$ in early embryonic development has been identified in studies indicating its presence in the chicken embryo. Iron participates in synthesis of nucleic acids and is an important structural co-factor for many proteins, including DNA synthesis and oxygen transport proteins (Tako \& Glahn, 2011). Similar results were obtained by other authors. Jones et al. (1981) have examined the effects of TCDD on normal and iron-deficient mice fed a casein-based diet. They found numerous pathological changes, including liver necrosis and cholan- giofibrosis. In general, iron deficiency did not decrease the activity of the hepatic mixed-function oxygenase systems. Iron deficiency protects against porphyria caused by TCDD, but protection against histological damage to the liver obtained through iron deficiency is incomplete (Jones et al., 1981). Moreover, Al-Bayati and others (Al-Bayati et al., 1987) had found that iron is involved in TCDD-induced lipid peroxidation. Wahaba and others (Wahaba et al., 1988) have studied the distribution of iron, copper, zinc and magnesium in hepatic subcellular fractions of male and female rats treated with TCDD. The iron content in livers from female animals was two times higher when compared to the male animals. Administration of TCDD had increased iron content in mitochondria of both, the female and male rats, and had decreased the iron content in microsomes of both sexes. Significant increases occurred with respect to the copper content in the whole liver, mitochondria and cytosol of male rats and in the whole liver and cytosol of female rats. Decreases in copper content in microsomes of male rats were observed following the TCDD treatment; however, TCDD produced no changes in the zinc content of hepatic subcellular fractions in either sex. In female TCDD-treated rats, magnesium content had increased in the whole liver, mitochondria, and cytosol, while magnesium content of microsomes was not altered. With respect to subcellular distribution of iron, copper, zinc and magnesium, TCDD produces varied effects. The altered distribution of some cations may contribute to the broad range of TCDD effects (Wahba et al., 1988). Avian embryos develop and grow based on energy and nutrients stored in the egg by the hen. In this sense, the breeder male contribution is not important. Follicular deposition of nutrients occurs over a wide time range, but becomes relevant during the week prior to ovulation. Amounts, but also forms, of nutrients deposited in the egg determine the success of embryo development and hatching of a healthy chick. $\alpha$-Tocopherol concentration in the egg yolk is correlated to its concentration in the feed. Moreover, its levels in the embryo are similar to those found in the yolk at early stages of incubation. The highest levels are found in the liver, but they are rapidly depleted after hatching. $\alpha$-Tocopherol has been correlated with breeding efficiency in several species, and with immune response in poultry. Heat stress increases metabolic peroxidation in poultry, and hens exposed to heat stress lay eggs with lower $\alpha$-tocopherol concentrations in the yolk. Maternal supplementation of $\alpha$-tocopherol levels, as high as $160 \mathrm{IU}$ in the feed may be required for chicks exposed to oxidative stress. In fact, chicken from young breeders presented lower mortality when fed 300 $\mathrm{IU} / \mathrm{kg}$ of $\alpha$-tocopherol (Vieira, 2007). Our study showed synergistic effects of $\alpha$-tocopherol with TCDD for copper, zinc and magnesium content, while $\alpha$-tocopherol alone does not influence the zinc and magnesium content in the liver.

\section{CONCLUSIONS}

Retarded liver development was observed in all experimental groups. Moderate increase in the iron content in the liver may be caused by antagonistic action of iron and $\alpha$-tocopherol in all experimental groups. Synergistic action of $\alpha$-tocopherol and TCDD has been noted with respect to the liver copper content. Moreover, $\alpha$-tocopherol alone has no influence on the magnesium and zinc content in the liver. 


\section{Acknowledgements}

The authors would like to thank Prof. Ireneusz Całkosiński (1951-2017) for inspiration and helpful advice, as well as help with respect to organization and ensuring welfare of the animals.

\section{Conflicts of Interest}

The authors declare that there is no conflict of interest regarding the publication of this paper.

\section{REFERENCES}

Al-Bayati ZAF, Stohs SJ (1987) The role of iron in 2,3,7,8-tetrachlorodibenzo-p-dioxin-induced lipid peroxidation by rat liver microsomes. Toxicology Lett 38: 115-121. https://doi.org/10.1016/03784274(87)90119-6

Alsharif NZ, Hassoun EA (2004) Protective effects of vitamin A and vitamin $\mathrm{E}$ succinate against 2,3,7,8-tetrachlorodibenzo-p-dioxin (TCDD)-induced body wasting, hepatomegaly, thymic atrophy, production of reactive oxygen species and DNA damage in C57BL/6J mice. Pharmacol Toxicol 95: 131-138. https://doi.org/10.1111/j.17427843.2004.950305.x

Birge WJ, Roberts OW, Black JA (1976) Toxicity of metal mixtures to chick embryos. Bull Environm Contam Toxicol 16: 314-324. PMID: 987815

Blankenship AL, Hilscherova K, Nie M, Coady KK, Villalobos SA, Kannan K, Powell DC, Bursian SJ, Giesy JP (2003) Mechanisms of TCDD-induced abnormalities and embryo lethality in white leghorn chickens. Comp Biochem Physiol C Toxicol Pharmacol: CBP 136: 47-62. PMID: 14522598

Całkosiński I (2008) The influence of tocopherol on diagnostic indexes of inflammatory reaction in rats undergoing dioxin exposition. Wroclaw Medical University.

Całkosiński I, Rosińczuk-Tonderys J, Bazan J, Dobrzyński M, Bronowicka-Szydełko A, Dzierzba K (2014) The influence of dioxin intoxication on the human system and possibilities of limiting its negative effects on the environment and living organisms. Ann Agric Environ Med 21: 518-524. https://doi. org/10.5604/12321966.1120594

Całkosiński I, Rosińczuk-Tonderys J, Bazan J, Dzierzba K, Całkosińska M, Majda J, Dobrzyński M, Bronowicka-Szydełko A (2013) The influence of 2,3,7,8-tetrachlorodibenzo-p-dioxin (TCDD) on hematological parameters during experimentally induced pleuritis in rats. Inflammation 36: 387-404. https://doi.org/10.1007/s10753-012-9558-y

Całkosiński I, Rosińczuk-Tonderys J, Szopa M, Dobrzyński M, Gamian A (2011) High doses of tocopherol in the prevention and potentiation of dioxin in experimental inflammation - potential application. Post Higieny Medycyny Doś 65: 143-157 (in Polish)

Cohen-Barnhouse AM, Zwiernik MJ, Link JE, Fitzgerald SD, Kennedy SW, Hervé JC, Giesy JP, Wiseman S, Yang Y, Jones PD, Wan Y, Collins B, Newsted JL, Kay D, Bursian SJ (2011) Sensitivity of Japanese quail (Coturnix japonica), common pheasant (Phasianus colchicus), and white leghorn chicken (Gallus gallus domesticus) embryos to in ovo exposure to TCDD, PeCDF, and TCDF. Toxicol Sci 119: 93-103. https://doi.org/10.1093/toxsci/kfq289

De Vries M, Kwakkel RP, Kijlstra A (2006) Dioxins in organic eggs: a review. NJAS - Wageningen J Life Sci 54: 207-221
Dobrzyński M, Całkosiński I, Przywitowska I, Kobierska-Brzoza J, Czajczyńska-Waszkiewicz A, Sołtan E, Parulska O (2009) Effects of dioxins in environmental pollution on development of tooth disorder. Pol J Environ Studies 18: 319-323

Gilani SH, Alibhai Y (1990) Teratogenicity of metals to chick embryos. J Toxicol Environ Hlth 30: 23-31. https://doi. org/10.1080/15287399009531407

Gostomska-Pampuch K, Ostrowska A, Kuropka P, Dobrzyński M, Ziółkowski P, Kowalczyk A, Gamian A, Całkosiński I (2017) Protective effects of levamisole, acetylsalicylic acid, and $\alpha$-tocopherol against dioxin toxicity measured as the expression of $\mathrm{AhR}$ and COX-2 in a chicken embryo model. Histochem Cell Biol 147: 523536. https://doi.org/10.1007/s00418-016-1528-2

Henschel K, Wenzel A, Diedrich M, Fliedner A (1997) Environmental hazard assessment of pharmaceuticals. Regul Toxicol Pharmacol 25: 220-225. https://doi.org/10.1006/rtph.1997.1102

Hilscherova K, Blankenship AL, Nie M, Coady KK, Upham BL, Trosko JE, Giesy JP (2003) Oxidative stress in liver and brain of the hatchling chicken (Gallus domesticus) following in ovo injection with TCDD. Comp Biochemi Physiol C Toxicol Pharmacol 136: 29-45. PMID: 14522597

Jones KG, Cole FM, Sweeney GD (1981) The role of iron in the toxicity of 2,3,7,8-tetrachlorodibenzo-(p)-dioxin (TCDD). Toxicol Appl Pharmacol 61: 74-88. PMID: 7292504

Mas A, Arola L (1985) Cadmium and lead toxicity effects on zinc, copper, nickel and iron distribution in the developing chick embryo. Comp Biochem Physiol C 80: 185-188. PMID: 2858342

Miles RD (2000) Ciéncia animal brasileira. (Brazilian Animal Science) (Vol. 2). Universidade Federal de Goiás (in Portuguese)

Richards MP (1991a) Mineral metabolism in the developing turkey embryo. I. The effects of developmental age and shell-less culture on trace element contents of selected tissues. Comp Biochem Physiol 100A: 1009-1016

Richards MP (1991b) Mineral metabolism in the developing turkey embryo. II. The role of the yolk sac. Comp Biochem Physiol 100A: 1017-1023

Richards MP, Steele NC (1987) Trace element metabolism in the developing avian embryo: a review. I Exp Zool. Supplement: Published under Auspices of the American Society of Zoologists and the Division of Comparative Physiology and Biochemistry 1: 39-51. PMID: 3298536

Sandrock BC, Kern SR, Bryan SE (1983) The movement of zinc and copper from the fertilized egg into metallothionein-like proteins in developing chick hepatic tissue. Biol Trace Elem Res 5: 503-515. https://doi.org/10.1007/BF02988942

Tako E, Glahn RP (2011) Iron status of the late term broiler (Gallus gallus) embryo and hatchling. Inte J Poultry Sci 10: 42-48

Taschetto D, Vieira SL, Angel CR, Stefanello C, Kindlein L, Ebbing MA, Simões CT (2017) Iron requirements of broiler breeder hens Poultry Sci 96: 3920-3927. https://doi.org/10.3382/ps/pex208

Vieira S (2007) Chicken embryo utilization of egg micronutrients. Rev Bras Cienc Avic 9: 1-8

Wahba ZZ, Al-Bayati ZA, Stohs SJ (1988) Effect of 2,3,7,8-tetrachlorodibenzo-p-dioxin on the hepatic distribution of iron, copper, zinc, and magnesium in rats. J Biochem Toxicol 3: 121-129. PMID: 3236332

White HB (1991) Maternal diet, maternal proteins and egg quality. In Egg Incubation: Its Effects on Embryonic Development in Birds and Reptiles. M. W. J. F. D. Charles Deeming ed, pp 1-5. Cambridge: Cambridge University Press, Cambridge, UK 